\title{
Stress Distribution Patterns Associated with Dental Implants with Varying Thread Designs, Dimensions and Splinting Conditions: A Photoelastic Analysis
}

\author{
Ashwini Narayankar ${ }^{1}$, Gunjan S Aswal ${ }^{2} \odot$, Shahbaz Ahmed ${ }^{3}$, Vinod Kumar $^{4} \odot$, Renu Rawat $^{5} \odot$, Nitin Prabhakar $^{6} \odot$
}

\begin{abstract}
Aims and objectives: To assess and compare the functional load distribution pattern in dental implants with different thread designs (V-shaped, square, and reverse buttress), length (long $=12-13 \mathrm{~mm}$, short $=8 \mathrm{~mm}$ ), diameter (narrow $=3.75 \mathrm{~mm}$, wide $=4.9-5 \mathrm{~mm}$ ), and splinting condition (splinted or non-splinted) using photoelastic analysis.

Materials and methods: Eight epoxy resin-based photoelastic models using a custom-designed acrylic mould measuring $75 \mathrm{~mm} \times 12 \mathrm{~mm} \times$ $30 \mathrm{~mm}$ were prepared, with three implants in each of the models. Dental implants were placed vertically and parallel to each other using a holding device and a surveyor. A polariscope was employed to view the fringes before and after applying the load. Fringe orders were observed and principal stress was calculated. Data was statistically analyzed using factorial ANOVA.

Results: In splinted and non-splinted conditions, the least principal stress (1.111-2.286 N/fringe $/ \mathrm{mm}^{2}$ and 1.363-3.082 N/fringe/ $/ \mathrm{mm}^{2}$, respectively) was associated with $V$ thread dental implants. Square thread (splinted 1.814-2.852 N/fringe $/ \mathrm{mm}^{2}$, non-splinted 1.866-3.336 N/fringe $/ \mathrm{mm}^{2}$ ) and reverse buttress thread (splinted 1.981-3.040 N/fringe $/ \mathrm{mm}^{2}$, non-splinted 1.971-3.586 N/fringe/ $/ \mathrm{mm}^{2}$ ) dental implants showed comparatively higher stress. Long and wide dental implants showed lesser principal stress when compared to short and narrow dental implants. Splinted dental implants presented lesser principal stress $\left(2.021 \mathrm{~N} /\right.$ fringe $\left./ \mathrm{mm}^{2}\right)$ in comparison to non-splinted dental implants $(2.731 \mathrm{~N} /$ fringe/mm²).

Conclusions: Thread design, dimension and splinting condition of the implants plays a significant role in reducing bone stress. Clinically, to enhance the long-term success of implant therapy, $V$ thread design, longer $(\geq 12-13 \mathrm{~mm})$ and wider $(\geq 4.9-5 \mathrm{~mm})$ implants shall be preferred over square or reverse buttress thread design, shorter $(\leq 8 \mathrm{~mm})$ and narrower $(\leq 3.75 \mathrm{~mm})$ implants. Splinting of dental implants effectively reduces principal stresses in the surrounding bone.

Clinical significance: Clinicians shall be able to use the findings of this study when selecting dental implants based on thread design, dimension, and the need to splint the dental implants for predictable treatment outcomes.

Keywords: Dental implants, Dental implant dimensions, Dental implant thread designs, Non-splinted, Photoelastic stress analysis, Splinted. World Journal of Dentistry (2022): 10.5005/jp-journals-10015-1885
\end{abstract}

\section{INTRODUCTION}

Dental implants have successfully entered the mainstream dental practice for the replacement of missing teeth. Implants replace teeth in the most natural way possible by anchoring an alloplastic material into the jaws to provide support and retention to the prosthesis. ${ }^{1}$ The titanium-based alloys possess properties that make them an ideal implant material. ${ }^{2}$ The general agreement is that excess stress to an implant interface may cause overload leading to implant failure. The clinical success and longevity of endosteal dental implants are related to the health of the surrounding crestal region of bone and soft tissue. ${ }^{3}$ The contact between the implant and the surrounding bone is crucial for the osseointegration of the implant which is necessary to resist the multidirectional masticatory forces and enhance the long-term success of the implant. ${ }^{4}$ The design and dimension of the dental implant plays a vital role in modifying the bone-implant interface. Commonly used thread designs are viz. $V$ thread, reverse buttress, and square thread. The effects of different threads in the load transmission potential and stimulatory capability have been successfully studied and continue to intrigue the researchers. ${ }^{5,6}$

Photoelastic stress analysis has been used for measuring the magnitude, direction, and distribution of principal stress in models that are transparent or translucent. In this technique, the stress fields are interpreted based on the interference fringes formed
${ }^{1}$ Department of Prosthodontics, SB Patil Dental College and Hospital, Bidar, Karnataka, India

${ }^{2}$ School of Dentistry and Oral Health, Fiji National University, Suva, Fiji

${ }^{3}$ Apollo Hospitals, Bengaluru, Karnataka, India

${ }^{4}$ Department of Periodontics, Jimma University, Jimma, Ethiopia

${ }^{5}$ Smilealign Dental Clinic, Bengaluru, Karnataka, India

${ }^{6}$ Department of Oral and Maxillofacial Surgery, College of Medicine and Health Sciences, Hawassa University, Ethiopia

Corresponding Author: Gunjan S Aswal, School of Dentistry and Oral Health, Fiji National University, Suva, Fiji, Phone: +6799737008 , e-mail: docgsaswal@gmail.com

How to cite this article: Narayankar A, Aswal GS, Ahmed S, et al. Stress Distribution Patterns Associated with Dental Implants with Varying Thread Designs, Dimensions and Splinting Conditions: A Photoelastic Analysis. World J Dent 2022;13(1):9-15.

Source of support: Nil

Conflict of interest: None

upon the passing of polarized light through the transparent, loaded models. A polariscope is required to view the stress distribution. ${ }^{7}$ Therefore, photoelastic stress analysis has become relevant for understanding the stress patterns generated upon loading a dental implant. Therefore, this study is aimed to determine the stress 
distribution pattern around implants with (V-shaped, square and reverse buttress), different lengths (long $\geq 12-13 \mathrm{~mm}$, short $\leq 8 \mathrm{~mm}$ ), and different diameters (narrow $\leq 3.75 \mathrm{~mm}$, Wide $\geq 4.9-5 \mathrm{~mm}$ ). Additionally, demonstrate the effect of splinting of implants on stress distribution patterns.

\section{Materials and Methods}

A total of 24 dental implants (MIS and EZ HI-TEC) with varying thread designs, lengths, and diameters were included in this study, refer Table 1.

\section{Preparation of the Photoelastic Model}

Eight photoelastic models were fabricated using acrylic sheet moulds measuring $75 \mathrm{~mm} \times 12 \mathrm{~mm} \times 30 \mathrm{~mm}$, sealed with cyanoacrylate glue. Three implants of varying thread designs, lengths, and diameters were positioned in each model using a holding device. It consists of an acrylic plate measuring $75 \mathrm{~mm} \times 12 \mathrm{~mm}$, with a hole drilled to accommodate the mandrel, which fitted snugly to the vertical spindles of the model surveyor. Further three holes were drilled in the acrylic sheet to accommodate the dental implants used for the experiment. The implants were positioned vertically on a glass plate with the holder of an implant touching the glass surface. The implant holding plate was lowered on these implants to the level of threads by pushing the vertical spindle of

Table 1: Characteristics of dental implants selected in the study

\begin{tabular}{lcc}
\hline Thread design & Length $(\mathrm{mm})$ & Diameter $(\mathrm{mm})$ \\
\hline Reverse buttress thread & 8 & 3.75 \\
Reverse buttress thread & 13 & 3.75 \\
Reverse buttress thread & 8 & 5 \\
Reverse buttress thread & 13 & 5 \\
Square thread & 8 & 3.75 \\
Square thread & 12 & 3.75 \\
Square thread & 8 & 4.9 \\
Square thread & 12 & 4.9 \\
V thread & 8 & 3.75 \\
V thread & 13 & 3.75 \\
V thread & 8 & 5 \\
V thread & 13 & 5
\end{tabular}

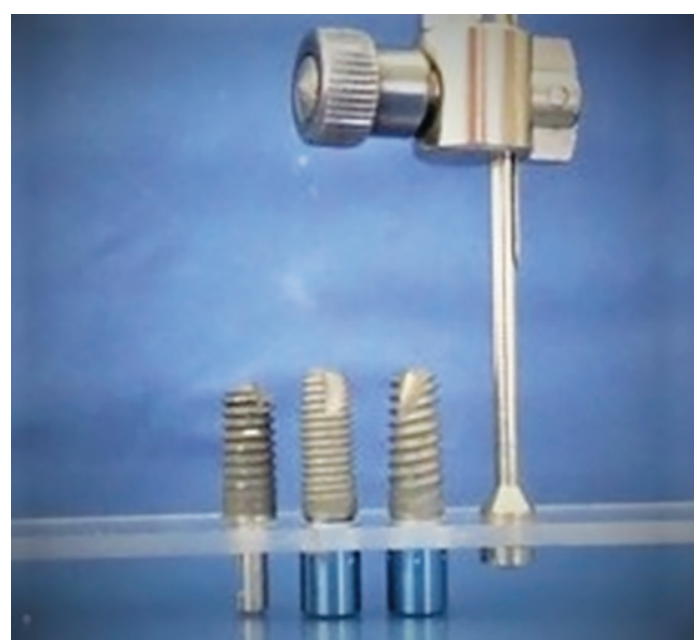

Fig. 1: Parallel placement of dental implants the surveyor (Fig. 1). These implants were fixed to an acrylic plate with sticky wax. The rectangular mould measuring $75 \mathrm{~mm} \times 12 \mathrm{~mm}$ $\times 30 \mathrm{~mm}$ was then fixed onto the holding device. A homogenous mix of epoxy resin with a hardener in a 10:1 ratio was carefully poured into the mould and was kept undisturbed for 24 hours for curing. It was removed from the mould once set to obtain the final specimen (Fig. 2). A casted superstructure over the implants was used to splint the implants (Fig 3).

\section{Photoelastic Analysis Using Polariscope}

A polariscope is a dark field instrument to view stress patterns. The phenomenon of color change observed in a polariscope is proportional to the magnitude of stress applied to the model. Uniform black color is an indication of zero stress. However, when the load is applied gradually to the model, the areas with high-stress accumulation begin to change color. The continued application of stress cause color change in the following order of blue, orange, green, red, yellow and purple. The purple fringe is extremely sensitive to stress alterations. Due to the distinctiveness and clear visibility, the purple fringe (tint-of-passage) is selected to mark the increment in relative retardation that equals a fringe in order of unity $(\mathrm{N}-1)$. Subsequently, higher integral fringe orders $(\mathrm{N}=2$, $\mathrm{N}=3$, etc) denote the recurrence of this pattern with greater relative retardation in the model under observation. Fringes are evaluated as per the color-coding provided in Table 2.

Photoelastic stress analysis was performed before the test and after applying a load of $100 \mathrm{~N}$. On loading the photoelastic model, the resultant stress produced a proportional optical effect of isochromatic fringes as viewed in a polariscope. Starting with the unloaded model followed with incremental loading, fringes appeared first at the most highly stressed points. As the load

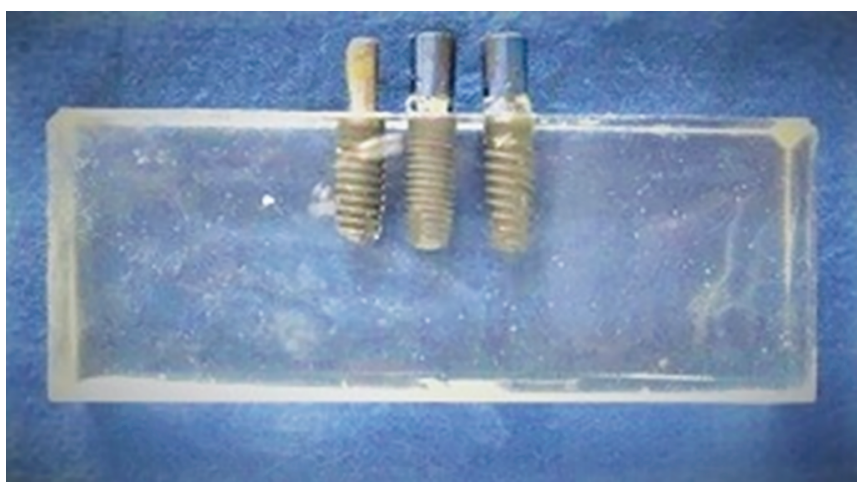

Fig. 2: Photoelastic model - non-splinted

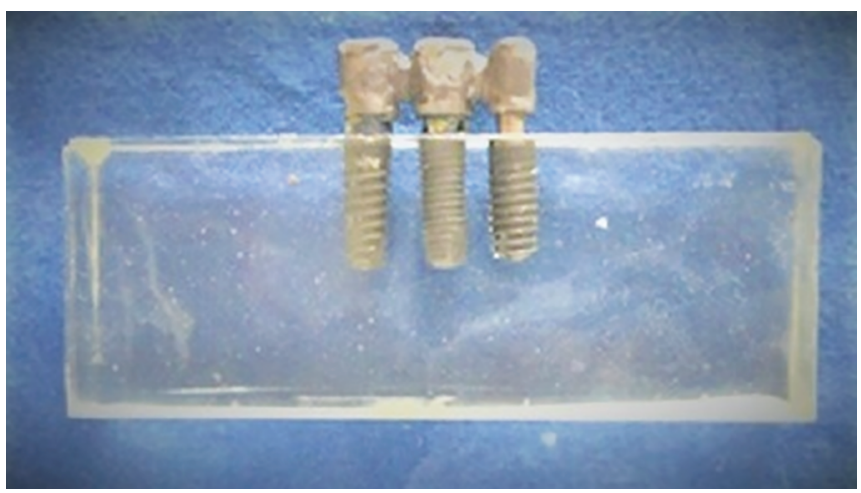

Fig. 3: Photoelastic model - splinted 
Table 2: Dominant isochromatic fringe colors for full-field interpretation

\begin{tabular}{lc}
\hline Color & Approximate fringe order \\
\hline Black & 0.0 \\
Yellow & 0.6 \\
Red & 0.9 \\
Purple (tint of passage) & 1.0 \\
Blue-green & 1.2 \\
Yellow & 1.5 \\
Red & 1.75 \\
Red/green transition & 2.0 \\
Green & 2.2 \\
Yellow & 2.5 \\
Red & 2.8 \\
Red/green transition & 3.0 \\
\hline
\end{tabular}

increased, new fringes appeared and the earlier fringes were pushed towards the areas of lower stress (Fig. 4).

\section{Fringe Order Calculation}

The fringe orders observed are proportional to the difference between principal stresses. Their relationship is expressed as per stress optic law. i.e., $\sigma 1-\sigma 2=\mathrm{Nf} / \mathrm{t}$.

Where $\sigma 1$, and $\sigma 2=$ algebraically maximum and minimum stress, in $\mathrm{N} / \mathrm{mm}^{2}$

$\mathrm{N}=$ fringe order, $\mathrm{f}=$ material fringe value, in $\mathrm{N} /$ Fringe $/ \mathrm{mm}$, $\mathrm{t}=$ thickness of the model in $\mathrm{mm}$. Since, for a given material and a light source, the value of ' $f$ ' and ' $t$ ' are constant, the $\sigma 1-\sigma 2$ value is a function of ' $N$ ' only. Therefore, at any point of interest where $\sigma 1-\sigma 2$ is to be determined, the fringe order ' $\mathrm{N}$ ' is measured accurately and precisely.
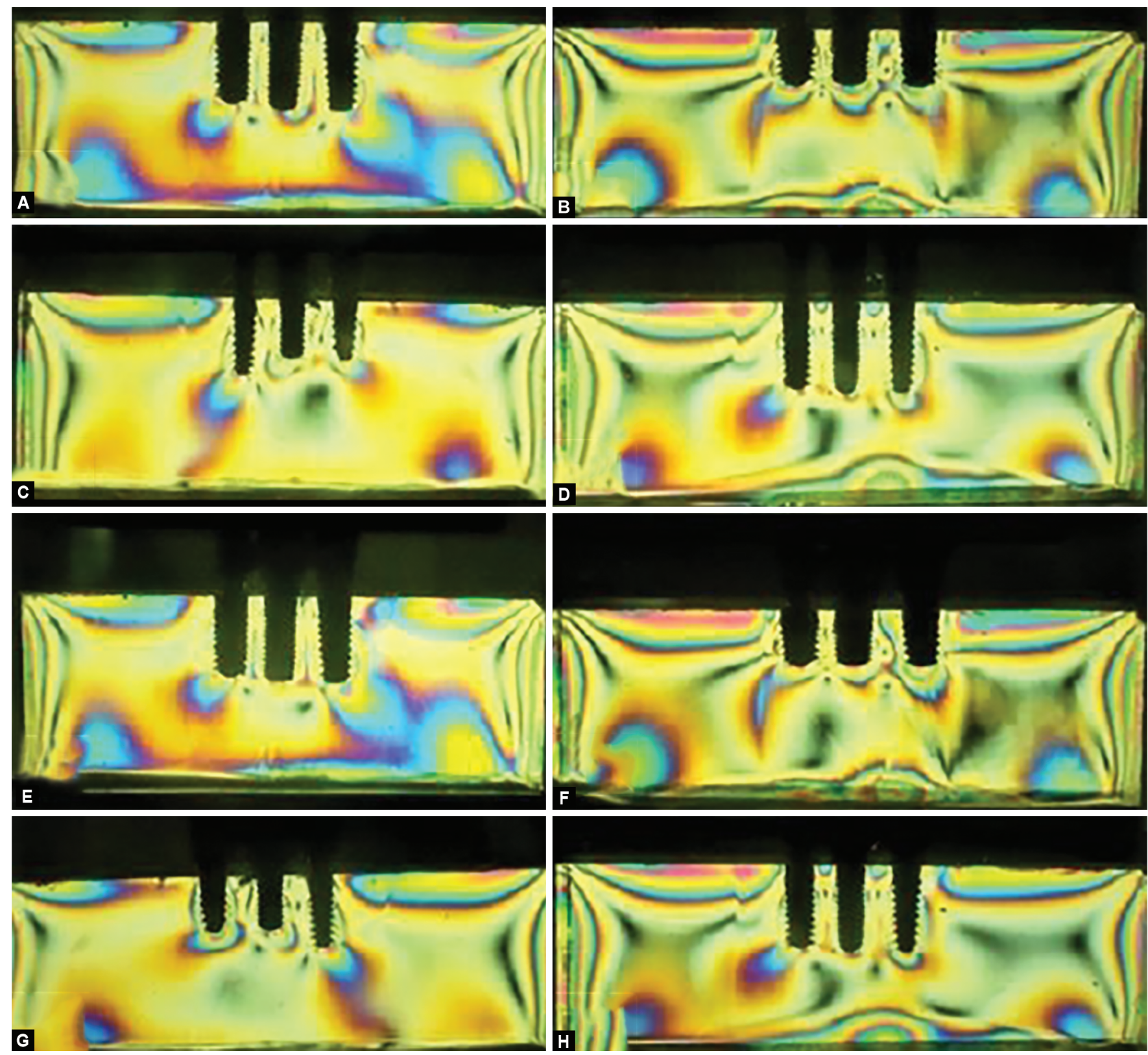

Figs. 4A to $\mathrm{H}$ : Photoelastic analysis - Fringes 
Stress Pattern Around Dental Implants

Table 3: Mean stress (N/fringe/ $\mathrm{mm}^{2}$ ) recorded in the combination of conditions, threads, length and diameter

\begin{tabular}{|c|c|c|c|c|c|c|c|c|}
\hline Condition & Thread & Length & Diameter & Mean & Std dev & Median & Min & Max \\
\hline \multirow[t]{12}{*}{ Splinted } & Reverse & $8 \mathrm{~mm}$ & $3.75 \mathrm{~mm}$ & 3.040 & 0.351 & 3.145 & 2.516 & 3.523 \\
\hline & Buttress & & $5 \mathrm{~mm}$ & 2.988 & 0.454 & 3.145 & 2.200 & 3.523 \\
\hline & & $13 \mathrm{~mm}$ & $3.75 \mathrm{~mm}$ & 2.591 & 0.229 & 2.642 & 2.200 & 2.780 \\
\hline & & & $5 \mathrm{~mm}$ & 1.981 & 0.277 & 2.044 & 1.510 & 2.200 \\
\hline & Square & $8 \mathrm{~mm}$ & $3.75 \mathrm{~mm}$ & 2.820 & 0.399 & 2.957 & 2.200 & 3.145 \\
\hline & & & $4.9 \mathrm{~mm}$ & 2.852 & 0.247 & 2.768 & 2.516 & 3.145 \\
\hline & & $12 \mathrm{~mm}$ & $3.75 \mathrm{~mm}$ & 2.810 & 0.283 & 2.768 & 2.516 & 3.145 \\
\hline & & & $4.9 \mathrm{~mm}$ & 1.814 & 0.265 & 1.887 & 1.510 & 2.200 \\
\hline & V thread & $8 \mathrm{~mm}$ & $3.75 \mathrm{~mm}$ & 2.286 & 0.480 & 2.516 & 1.510 & 2.768 \\
\hline & & & $5 \mathrm{~mm}$ & 1.636 & 0.425 & 1.699 & 1.132 & 2.200 \\
\hline & & $13 \mathrm{~mm}$ & $3.75 \mathrm{~mm}$ & 1.174 & 0.247 & 1.195 & 0.755 & 1.510 \\
\hline & & & $5 \mathrm{~mm}$ & 1.111 & 0.185 & 1.132 & 0.755 & 1.258 \\
\hline \multirow[t]{12}{*}{ Non-splinted } & Reverse & $8 \mathrm{~mm}$ & $3.75 \mathrm{~mm}$ & 3.397 & 0.195 & 3.523 & 3.145 & 3.523 \\
\hline & Buttress & & $5 \mathrm{~mm}$ & 3.586 & 0.249 & 3.649 & 3.145 & 3.775 \\
\hline & & $13 \mathrm{~mm}$ & $3.75 \mathrm{~mm}$ & 2.988 & 0.454 & 3.145 & 2.200 & 3.523 \\
\hline & & & $5 \mathrm{~mm}$ & 1.971 & 0.408 & 2.044 & 1.510 & 2.516 \\
\hline & Square & $8 \mathrm{~mm}$ & $3.75 \mathrm{~mm}$ & 3.040 & 0.351 & 3.145 & 2.516 & 3.523 \\
\hline & & & $4.9 \mathrm{~mm}$ & 3.336 & 0.317 & 3.523 & 2.768 & 3.532 \\
\hline & & $12 \mathrm{~mm}$ & $3.75 \mathrm{~mm}$ & 2.873 & 0.393 & 2.768 & 2.516 & 3.523 \\
\hline & & & $4.9 \mathrm{~mm}$ & 1.866 & 0.309 & 1.887 & 1.510 & 2.200 \\
\hline & V thread & $8 \mathrm{~mm}$ & $3.75 \mathrm{~mm}$ & 3.082 & 0.284 & 3.145 & 2.768 & 3.523 \\
\hline & & & $5 \mathrm{~mm}$ & 2.978 & 0.362 & 2.957 & 2.516 & 3.523 \\
\hline & & $13 \mathrm{~mm}$ & $3.75 \mathrm{~mm}$ & 1.772 & 0.333 & 1.887 & 1.258 & 2.200 \\
\hline & & & $5 \mathrm{~mm}$ & 1.363 & 0.167 & 1.384 & 1.132 & 1.510 \\
\hline
\end{tabular}

\section{Material Fringe Constant Calculation}

A circular specimen measuring $120 \mathrm{~mm} \times 12 \mathrm{~mm}$ was fabricated using the epoxy resin. Specimens were subjected to polariscope evaluation for photoelastic analysis. Load and the corresponding fringe orders were noted. First-order, second-order, and third-order fringe corresponded to a load of $65 \mathrm{~kg}, 97 \mathrm{~kg}$, and $138 \mathrm{~kg}$, respectively. The following formula was used to ca lculate the material fringe constant.

$f=(8 / \pi D)(P / N)$, where $P / N=[N \Sigma X Y-\Sigma X \Sigma Y] /\left[N \Sigma X^{2}-(\Sigma X)^{2}\right]$

$X$ - Fringe order, $Y$ - Load in N, D - Diameter of the specimen

$$
\begin{aligned}
\mathrm{P} / \mathrm{N} & =[\mathrm{N} \Sigma X Y-\Sigma X \Sigma Y] /\left[\mathrm{N} \Sigma \mathrm{X}^{2}-\left(\sum X\right)^{2}\right] \\
\mathrm{P} / \mathrm{N} & =[(4 \times 673)-(6 \times 300)] /\left[(4 \times 14)-6^{2}\right] \\
& =44.6 \mathrm{~kg} / \text { fringe }
\end{aligned}
$$

This $\mathrm{P} / \mathrm{N}$ value is put into the formula for the calculation of material fringe constant,

$$
\begin{aligned}
\mathrm{f} & =(8 / \pi \mathrm{D})(\mathrm{P} / \mathrm{N}) \\
& =[8 / 3.14 \times 75] \times[44.6] \\
& =1.51 \mathrm{~kg} / \mathrm{mm} / \text { fringe } \\
& =15.1 \mathrm{~N} / \mathrm{mm} / \text { fringe }
\end{aligned}
$$

Using this material fringe constant (f), principal stress was calculated for each specimen.

Principal stress $=\mathrm{N}^{*} \mathrm{f} / \mathrm{t}$ in $\mathrm{N} /$ fringe $/ \mathrm{mm}^{2}, \mathrm{~N}=$ fringe order, $\mathrm{f}=$ material fringe constant in $\mathrm{N} /$ fringe $/ \mathrm{mm}, \mathrm{t}=$ thickness of the model in $\mathrm{mm}$.

\section{Results and Statistical Analysis}

The results of the current investigation are summarized in Tables 3 and 4 . The mean principal stress associated with $\mathrm{V}$ thread design was
Table 4: Mean stress (N/fringe/ $/ \mathrm{mm}^{2}$ ) recorded in the combination of conditions, threads, length and diameter

\begin{tabular}{lcc}
\hline Specimen description & $\begin{array}{l}\text { Mean principal stress } \\
\left(\mathrm{N} / \text { fringe } / \mathrm{mm}^{2}\right)\end{array}$ & $\begin{array}{l}\text { Mean principal stress } \\
\left(\mu \text { strain/fringe } / \mathrm{mm}^{2}\right)\end{array}$ \\
\hline Splinted condition & 2.021 & 101.05 \\
Non-splinted condition & 2.731 & 136.55 \\
\hline
\end{tabular}

$1.111-2.286 \mathrm{~N} /$ fringe/ $/ \mathrm{mm}^{2}$ in splinted conditions and 1.363-3.082 N/ fringe $/ \mathrm{mm}^{2}$ in non-splinted conditions. In increasing order, this was followed by square thread with principal stress of $1.814-2.852 \mathrm{~N} /$ fringe $/ \mathrm{mm}^{2}$ in splinted condition and $1.866-3.336 \mathrm{~N} /$ fringe $/ \mathrm{mm}^{2}$ in non-splinted condition. The highest mean stress was observed with reverse buttress thread, which was in the range of 1.981-3.040 N/ fringe $/ \mathrm{mm}^{2}$ in splinted condition and $1.971-3.586 \mathrm{~N} /$ fringe $/ \mathrm{mm}^{2}$ in non-splinted condition. Overall, long and wide dental implants were associated with lower mean principal stress compared to short and narrow dental implants. Splinted dental implants presented a mean principal stress of $2.021 \mathrm{~N} /$ fringe $/ \mathrm{mm}^{2}$ whereas non-splinted implants resulted in mean principal stress of $2.731 \mathrm{~N} /$ fringe $/ \mathrm{mm}^{2}$.

The recorded data was subject to the Factorial ANOVA statistical test (Table 5). Higher mean stress was recorded with non-splinted implants in comparison to splinted implants and the difference between them was found to be statistically significant $(p<0.001)$. Among the three threads, higher mean stress was recorded in reverse buttress followed by square and $V$ thread respectively. The difference in mean stress was found to be statistically significant between Reverse Buttress and V thread $(p<0.001)$ as well as between square and $V$ thread $(p<0.001)$. At 8 mm length, we noticed a higher mean stress compared to $13 \mathrm{~mm}$ length and the difference 
Stress Pattern Around Dental Implants

Table 5: Statistical analysis

\begin{tabular}{|c|c|c|c|c|c|}
\hline Source $\left({ }^{*}=\right.$ times $)$ & $D f$ & Sum of squares (SS) & Mean SS & $F$ & $p$-value $\left({ }^{*}=\right.$ significant $)$ \\
\hline Splinting Condition & 1 & 6.6263 & 6.6263 & 60.409 & $<0.001^{*}$ \\
\hline Thread & 2 & 22.0889 & 11.0444 & 100.687 & $<0.001^{*}$ \\
\hline Length & 1 & 28.7743 & 28.7743 & 262.323 & $<0.001^{*}$ \\
\hline Diameter & 1 & 4.8253 & 4.8253 & 43.991 & $<0.001^{*}$ \\
\hline Condition * Thread & 2 & 1.9205 & 0.9602 & 8.754 & $<0.001^{*}$ \\
\hline Condition * Length & 1 & 1.4974 & 1.4974 & 13.651 & $<0.001^{*}$ \\
\hline Thread * Length & 2 & 1.3293 & 0.6646 & 6.059 & $0.003^{*}$ \\
\hline Condition ${ }^{*}$ Thread ${ }^{*}$ Length & 2 & 0.2523 & 0.1261 & 1.150 & 0.320 \\
\hline Condition * Diameter & 1 & 0.0206 & 0.0206 & 0.188 & 0.666 \\
\hline Thread * Diameter & 2 & 0.0768 & 0.0384 & 0.350 & 0.705 \\
\hline Condition * Thread * Diameter & 2 & 0.0774 & 0.0387 & 0.353 & 0.703 \\
\hline Length * Diameter & 1 & 3.6322 & 3.6322 & 33.113 & $<0.001^{*}$ \\
\hline Condition * Length * Diameter & 1 & 0.8214 & 0.8214 & 7.489 & $0.007^{*}$ \\
\hline Thread * Length * Diameter & 2 & 2.8348 & 1.4174 & 12.922 & $<0.001^{*}$ \\
\hline Condition ${ }^{*}$ Thread ${ }^{*}$ Length ${ }^{*}$ Diameter & 2 & 0.1444 & 0.0722 & 0.658 & 0.520 \\
\hline
\end{tabular}

between them was statistically significant $(p<0.001)$. Between the two types of diameters, higher mean stress was recorded at $3.75 \mathrm{~mm}$ compared to $5 \mathrm{~mm}$ and the difference between them was found to be statistically significant $(p<0.001)$.

The mean stress was found to be higher in non-splinted conditions compared to splinted conditions among all the threads and lengths. This interaction was found to be statistically significant $(p<0.001)$. The non-splinted condition recorded higher mean stress compared to the splinted condition with different diameters, the interaction was not statistically significant $(p>0.05) . V$ thread yielded a lower mean stress compared to the other threads at both the lengths as well as both the diameters. Reverse buttress yielded a higher mean stress compared to the square thread at both the lengths and the diameters. The interaction of thread and length was found to be statistically significant $(p<0.01)$. Higher mean stress was recorded at $8 \mathrm{~mm}$ length compared to $13 \mathrm{~mm}$ length at both the diameters and this interaction was found to be statistically significant $(p<0.001)$.

\section{Discussion}

Dental implants are subject to multidirectional masticatory forces in the oral cavity. In function, an ideal dental implant should distribute the load to the underlying bone. ${ }^{8}$ Unlike the natural teeth, force is concentrated more at the crest of the ridge around the implant. Natural teeth have periodontal ligament that takes up the primary load whereas in dental implants the whole load is taken up by the bone. ${ }^{9-11}$ Thread design is an important aspect considered in the biomechanical optimization of dental implants. The shape of the implant determines the surface area available for stress transfer. ${ }^{12}$ Threads are incorporated into the design so that shear forces can be better endured. Threads are used to enhance initial contact and stability, augment implant surface area and also bolster dissipation of masticatory stress. ${ }^{13}$

The photoelastic analysis is widely used in dentistry to study the biomechanical stress transfer in several kinds of prostheses. It provides quantitative evidence of highly stressed areas and peak stress at the surface and interior points of the structure. ${ }^{14}$ The polariscope is an optical instrument that utilizes the properties of polarized light in its operation. Upon load application, fringes start appearing at most highly stressed points. ${ }^{15}$ The photoelastic fringes observed in this work provide an idea of how the regions around the implants were stressed and thus stress per fringe can be quantified by the formula. Similar to the fringe pattern observed in this study, Yacoub et al. demonstrated that the stress concentrated areas were seen at the cervical and at the apical region of the dental implant which will be seen as colored fringes. ${ }^{16}$

Threads, due to their uneven contour, generate a heterogeneous stress field, which matches the physiologic overload zone, thus prompting new bone formation. ${ }^{11}$ Thread patterns in dental implants currently range from micro threads near the neck of the implant to broad macro threads on the mid-body and a variety of altered pitch threads to induce self-tapping and bone compression. ${ }^{17}$ The $V$-shaped thread was more effective in reducing stress in the current study. It primarily resists the tensile stress on the superior surface of the threads, and it is virtually zero normal stress on the inferior surface of the threads. The shear stress on the threads is primarily in the same direction except at the thread junction points where stress concentration occurs. ${ }^{18}$ Contrary to the results of this study, Kong et al reported that the stress distribution was better with reverse buttress than $\mathrm{V}$ thread and square thread designs. $^{13}$

Implant length plays an important role in distributing forces to the underlying bone that is longer the dental implant it better dissipates the masticatory forces. Longer dental implants can provide resistance to torque or shear forces by increasing the bone to the implant contact area so that stress can be dissipated over larger areas. ${ }^{19}$ The surface area of each implant is related directly to the width of the implant. Some studies have suggested that an increase in implant width is more important than an increase in length in reducing stress. ${ }^{20}$ Implants of large diameter have a greater range of bone contact than narrow implants which is due to their superior circumferential bone contact. Each $0.25 \mathrm{~mm}$ increase in implant diameter may increase the overall surface area $5-10 \%$ in a cylinder implant body. The supplemental implant support gained from the greater diameter not only decreases stress but also decreases the likelihood of implant fracture. $11,21,22$

Splinting of the implant crowns effectively enhances the bone surface area, favourably distributing the acting forces on the implants, and minimizing transfer of non-vertical load to the bone- 
implant interface. ${ }^{23-25}$ Supporting the findings of this study, a similar photoelastic study suggested that splinted restorations resulted in a more uniform sharing and distribution of stress between the implants, when subjected to eccentric forces in particular. Thus, splinting of implants was recommended to avoid implant failure, especially with compromised surrounding bone. ${ }^{26,27}$ A randomized controlled study concluded that the difference in bone loss between the groups was only $0.1 \mathrm{~mm}$, which was not considered clinically meaningful. ${ }^{28}$ However, the concept of splinting adjacent implants to lower the loading of the supporting structures requires further investigation.

\section{Limitations}

The current photoelastic study presents some limitations that make it impossible to precisely simulate clinical experiments. First, the inability to produce absolute bubble-free epoxy models and the inadvertent inaccurate positioning of the implants in the photoelastic model, which could have resulted in altered fringes. Second, photoelastic analysis cannot consider the influence of different forces during a chewing cycle and the forces applied by the surrounding muscles. Third, the forces were applied over the implants unlike the crowns in the real situation.

\section{Conclusion}

Within the limitations of this investigation, it may be concluded that the thread design, dimension, and the splinting condition of the implants play significant roles in reducing bone stress. Clinically, when settling on the crucial decision concerning the appropriate selection of dental implants, $V$ thread design, longer $(\geq 12-13 \mathrm{~mm})$ and wider $(\geq 4.9-5 \mathrm{~mm})$ implants shall be preferred over square or reverse buttress thread design, shorter $(\leq 8 \mathrm{~mm})$ and narrower $(\leq 3.75 \mathrm{~mm})$ implants. With multiple implants, splinting of the implants may be considered to minimize the principal stress around the implants, particularly in instances of poor bone quality. Additionally, with shorter implants, due to the associated vertical cantilevering, splinting of dental implants may reduce the overall stress in the surrounding bone and enhance the long-term success of the implant therapy.

\section{Future Directions}

The authors suggest finite element stress analysis and in-vivo studies with a similar configuration of dental implants to compare and affirm the results of the current study. Furthermore, future studies are encouraged that determine the effect of bone attributes on stress distribution patterns around dental implants to enhance the predictability of implant therapy.

\section{ORCID}

Gunjan S Aswal ๑ https://orcid.org/0000-0003-2641-1601

Vinod Kumar $\odot$ https://orcid.org/0000-0003-4184-4341

Renu Rawat ๑ https://orcid.org/0000-0003-0835-1166

Nitin Prabhakar ๑ https://orcid.org/0000-0002-4836-3279

\section{References}

1. Dewan SK, Arora A, Sehgal M, et al. Implant failures: a broader perspective. J Dent Implant 2015;5:53-59. DOI: 10.4103/09746781.154441
2. Duraccio D, Mussano F, Faga MG. Biomaterials for dental implants: current and future trends.J Mater Sci 2015;50:4779-4812. DOI: 10.1007/ s10853-015-9056-3

3. Duyck J, Vandamme K. The effect of loading on peri-implant bone: a critical review of the literature. J Oral Rehab 2014;41:783-794. DOI: 10.1111/joor.12195

4. Rosa $M B$, Albrektsson $T$, Francischone $C E$, et al. The influence of surface treatment on the implant roughness pattern. J Appl Oral Sci 2012:550-555. DOI: 10.1590/s1678-77572012000500010

5. Misch CE, Strong T, Bidez MW. Scientific rationale for dental implant design. In: Misch CE (ed.), Contemporary Implant Dentistry. 3rd ed. St. Louis, Mosby, 2008:pp 200-209. DOI: 10.1016/B978-0-323-07845$0.00015-4$

6. Bolind $\mathrm{PK}$, Johansson $\mathrm{CB}$, Becker W, et al. A descriptive study on retrieved non-threaded and threaded implant designs. Clin Oral Implants Res 2005;16(4):447-455. DOI: 10.1111/j.16000501.2005.01129.x

7. Orr JF, Finlay JB. Photoelastic stress analysis. In: Orr JF, Shelton JC (eds). Optical Measurement Methods in Biomechanics. Springer, Boston, MA. 1997. DOI: 10.1007/978-0-585-35228-2_1

8. Soncini M, Rodriguez Y, Pietrabissa R, et al. Experimental procedure for the evaluation of the mechanical properties of the bone surrounding dental implants. Biomaterials 2002;23:9-17. DOI: 10.1016/ s0142-9612(01)00073-4

9. Robinson D, Aguilar L, Gatti A, et al. Load response of the natural tooth and dental implant: a comparative biomechanics study. J Adv Prosthodont 2019;11(3):169-178. DOI: 10.4047/jap.2019.11.3.169

10. Álvarez-Arenal Á, Segura-Mori L, Gonzalez-Gonzalez I, et al. Stress distribution in the transitional peri-implant bone in a single implantsupported prosthesis with platform-switching under different angulated loads. J Odontol 2017;105(1):68-75. DOI: 10.1007/s10266016-0237-6

11. Steigenga JT, Al-Shammari KF, Nociti FH, et al. Dental implant design and its relationship to long term implant success. Implant Dent 2003;12:306-317. DOI: 10.1097/01.id.0000091140.76130.a1

12. Herekar MG, Patil VN, Mulani SS, et al. The influence of thread geometry on biomechanical load transfer to bone: a finite element analysis comparing two implant thread designs. Dent Res J (Isfahan) 2014;11(4):489-494. PMID: 25225563; PMCID: PMC4163828.

13. Kong L, Liu B, Li D, et al. Comparative study of 12 thread shapes of dental implant designs: a three-dimensional finite element analysis. World J Model Simul 2006;2(2):134-140. Corpus ID: 16745111.

14. Corrêa C, Ribeiro A, Reis JM, et al. Photoelasticity in dentistry: a literature review. Medicine 2014;11(2):178-184. Available at: <http:// hdl.handle.net/11449/125696>.

15. Ueda C, Markarian RA, Sendyk CL, et al. Photoelastic analysis of stress distribution on parallel and angled implants after installation of fixed prostheses. Braz Oral Res 2004;18(1):45-52. DOI: 10.1590/ s1806-83242004000100009

16. Yacoub N, Ismail YH, Mao JJ. Transmission of bone strain in the craniofacial bones of edentulous human skulls upon dental implant loading, J Prosthet Dent 2002;88:192-199. DOI: 10.1067/ mpr.2002.127401

17. Frost HM. Bone "mass" and the "mechanostat": a proposal. Anat Rec 1987;219(1):1-9. DOI: 10.1002/ar.1092190104

18. Faegh $S$, Mechanism of load transfer along the bone-dental implant interface, Mechanical Engineering Master's Thesis, Paper 18. 2009. http://hdl.handle.net/2047/d20000013

19. Geng JP, Ma QS, Xu W, et al. Finite element analysis of four thread form configurations in a stepped screw implant. J Oral Rehabil 2004;31:233-1239. DOI: 10.1046/j.0305-182X.2003.01213.x

20. Lin CL, Kuo YC, Lin TS. Effects of dental implant length and bone quality on biomechanical responses in bone around implants: a 3D non-linear finite element analysis. Biomed Eng Appl Basis Comm 2005;17:44-49. DOI: 10.4015/S1016237205000081

21. Li T, Hu K, Cheng L, et al. Optimum selection of the dental implant diameter and length in the posterior mandible with poor bone 
quality-A 3D finite element analysis. Appl Math Model 2011;35:446456. DOI: $10.1016 /$ j.apm.2010.07.008

22. Elsayed MD. Biomechanical factors that influence the bone-implant interface. Res Rep Oral Maxillofac Surg 2019;3:23. DOI: 10.23937/ IAOMS-2017/1710023

23. Grossman Y, Finger IM, Block MS. Indications for splinting implant restorations. J Oral Maxillofac Surg 2005;63:1642-1652. DOI: 10.1016/j. joms.2005.05.149

24. Nissan J, Ghelfan O, Gross M, et al. Analysis of load transfer and stress distribution splinted and unsplinted implant-supported fixed cemented restorations. J Oral Rehabil 2010;37:658-752. DOI: 10.1111/j.1365-2842.2010.02096.x

25. Jofre J, Cendoya P, Munoz P. Effect of splinting mini-implants on marginal bone loss: a biomechanical model and clinical randomized study with mandibular overdentures. Int J Oral Maxillofac Implants 2010;25(6):1137-1144.
26. Guichet DL, Caputo AA, Choi H, et al. Passivity of fit and marginal opening in screw or cement retained implant fixed partial denture designs. Int J Oral Maxillofac Implants 2000;15:239-246. PMID: 10795456.

27. De Souza Batista VE, Verri FR, Lemos CAA, et al. Should the restoration of adjacent implants be splinted or non-splinted? A systematic review and meta-analysis. J Prosthet Dent 2019;121(1):41-51. DOI: 10.1016/j. prosdent.2018.03.004

28. Vigolo $\mathrm{P}$, Mutinelli S, Zaccaria M, et al. Clinical evaluation of marginal bone level change around multiple adjacent implants restored with splinted and non-splinted restorations: a 10-year randomized controlled trial. Int J Oral Maxillofac Implants 2015;30(2):411-418. DOI: $10.11607 /$ jomi.3837 